\title{
Systematic review: total knee arthroplasty (TKA) in patients with pigmented villonodular synovitis (PVNS)
}

\author{
Yi Chuen $\operatorname{Tan}^{1 * \dagger} \mathbb{D}$, Jia Yin $\operatorname{Tan}^{2+}$ and Konstantinos Tsitskaris ${ }^{3}$
}

\begin{abstract}
Background: To determine the functional outcomes, complications and revision rates following total knee arthroplasty (TKA) in patients with pigmented villonodular synovitis (PVNS).

Materials and methods: We conducted a systematic review of the literature. Five studies with a total of 552 TKAs were included for analysis. The methodological quality of the articles was evaluated using the Strengthening the Reporting of Observational Studies in Epidemiology (STROBE) scale. Functional outcomes, complications and revision rates were assessed. The mean age was 61 years (range 33-94 years) and the mean follow-up period was 61.1 months (range $0.2-35$ years).

Results: All the studies reported improvement in knee function following TKA. Post-operative stiffness was the most frequently reported complication, affecting $32.7 \%(n=32)$ of patients in our review. Symptomatic recurrence of PVNS, component loosening, tibial-component fracture, instability and periprosthetic infection were the main factors leading to the need for revision TKA.

Conclusion: The findings of this review support the use of TKA to alleviate the functional limitations and pain due to knee degeneration in patients with PVNS. The operating surgeon should be aware of the increased risk of postoperative stiffness, as well as a potentially higher risk of infection. Implant survival should also be considered inferior to the one expected for the general population undergoing TKA.
\end{abstract}

Keywords: Pigmented villonodular synovitis, Total knee arthroplasty, Functional outcomes, Complications

\section{Introduction}

Pigmented villonodular synovitis (PVNS) is a benign proliferative condition which affects the synovial tissue and is a subtype of tenosynovial giant-cell tumor [1]. This rare condition is believed to be an inflammatory process and can either be localized (L-PVNS) or diffuse (D-PVNS), the latter accounting for the majority of cases [2]. PVNS commonly presents

\footnotetext{
*Correspondence: yi.tan@nhs.net

${ }^{\dagger}$ Yi Chuen Tan and Jia Yin Tan are both joint first authors, both contributing equally to the write-up of this manuscript.

${ }^{1}$ Whipps Cross University Hospital, Barts Health NHS Trust, Whipps Cross Road, Leytonstone, London E11 1NR, UK

Full list of author information is available at the end of the article
}

unilaterally in the knee, hip and ankle joints, with the diffuse form typically characterized by joint pain, swelling and stiffness, while the localized form presents with locking, catching and joint instability. The disease typically affects individuals aged $30-40$ years old but can affect patients in all age groups [3].

The etiology of PVNS is still unclear, with some believing that the disease stems from chronic inflammation $[4,5]$, whereas others classify it as a benign tumor with low metastasizing potential $[6,7]$. Trauma has also been implicated in the development of PVNS, but with poor evidence supporting a causal link between the two.

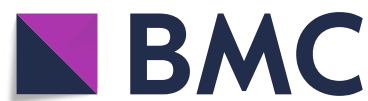

Part of Springer Nature
(9) The Author(s). 2021 Open Access This article is licensed under a Creative Commons Attribution 4.0 International License, which permits use, sharing, adaptation, distribution and reproduction in any medium or format, as long as you give appropriate credit to the original author(s) and the source, provide a link to the Creative Commons licence, and indicate if changes were made. The images or other third party material in this article are included in the article's Creative Commons licence, unless indicated otherwise in a credit line to the material. If material is not included in the article's Creative Commons licence and your intended use is not permitted by statutory regulation or exceeds the permitted use, you will need to obtain permission directly from the copyright holder. To view a copy of this licence, visit http://creativecommons.org/licenses/by/4.0/ The Creative Commons Public Domain Dedication waiver (http://creativecommons.org/publicdomain/zero/1.0/) applies to the data made available in this article, unless otherwise stated in a credit line to the data. 
Treatment for PVNS aims at removing the pathological lesion(s) either through open or arthroscopic synovectomy [8]. A meta-analysis by Aurégan et al. suggests that there were no significant differences between open or arthroscopic synovectomy when it came to functional outcome and local recurrence in both patients with L-PVNS and D-PVNS of the knee; however, in DPVNS, there were fewer post-operative complications when performing arthroscopic synovectomy [9]. Another meta-analysis conducted by Mollon et al. [10] suggests that open synovectomy or synovectomy combined with peri-operative radiotherapy for D-PVNS is associated with a reduced rate of recurrence and has good functional outcomes; however, the authors note that open synovectomy also brings an increased risk of stiffness when compared to arthroscopic synovectomy [10]. In the setting of PVNS with established degenerative changes, total knee arthroplasty (TKA) should be considered [9].

With the increasing number of TKAs performed each year, arthroplasty surgeons are likely to encounter cases of PVNS with established degenerative changes. Understanding the challenges associated with this group of patients is, hence, very important. Our initial intent was to perform a meta-analysis on TKA as a treatment modality for PVNS; however, due to both the disease's rarity and the scarcity of available literature, we have, therefore, decided to perform a systematic review of the literature instead to determine the functional outcomes and complications of TKA in patients with PVNS of the knee.

\section{Materials and methods}

\section{Search strategy}

The literature search was conducted on Medline and EMBASE on 16 April 2020 by research librarians at two independent hospitals. Keywords used for the searches were "Pigmented Villonodular Synovitis" OR "Pigmented Villonodular Tenosynovitis" OR "Giant Cell Tumour of Tendon Sheath" AND "Arthroplasty, Replacement, Knee." All relevant studies between 1946 and 2020 were identified in accordance with the Preferred Reporting Items for Systematic review and Meta-Analysis (PRIS MA) guidelines. All three authors then identified relevant studies by assessing the bibliographies of the included papers. The selected articles adhered to the PICO criteria for systematic reviews Population, Intervention, Comparison and Outcomes (PICO) criteria for systematic reviews.

\section{Eligibility criteria}

Our inclusion criteria for the study were as follows: (1) the studies selected should be about TKA as a treatment modality in PVNS, (2) the articles should be written in
English, (3) the articles would report the functional outcomes post TKA and (4) the articles would report on complications post TKA.

Our exclusion criteria were: (1) articles not reporting on the functional outcomes, (2) articles which included arthroscopic treatment of PVNS instead of TKA and (3) case reports which did not include the functional outcomes post TKA.

After removal of duplicate articles, a full-text review of the selected studies was undertaken by two authors (YCT and KT).

\section{Data extraction}

One reviewer (YCT) extracted data from the selected papers using a standardized data collection form. Information relating to the number of patients, their demographics, follow-up period, complications, revision rates, implant survival rates, recurrence and pre-operative and post-operative clinical and functional outcomes were compiled into a spreadsheet which was later checked by the second reviewer (JYT). There were no inconsistencies in the results.

\section{Quality assessment}

The Strengthening the Reporting of Observational Studies in Epidemiology (STROBE) scale was used to evaluate the articles [11]. It was performed independently by both reviewers (YCT and JYT). This scale comprised a 22-item checklist that assesses the title, abstract, introduction, methods, results, discussion and other information in an article. It was then divided into 34 individual items, for which each item received a score of 0 to 1 . Each article was scored out of a total score of 34 . The scores were compared between both reviewers and discrepancies discussed until consensus was reached. The total score was converted to represent a percentage form. Evaluation of quality assessment was classified into three categories, with more than $80 \%$ of criteria met $=$ ,++ 50 to $80 \%$ of criteria met $=+$ and less than $50 \%$ of criteria met $=-$.

The four studies included were small to medium retrospective case series $(n=10-48$ patients, $11-48$ TKAs) describing the outcome of TKA in patients with PVNS. Our largest study was by Casp et al. ( $n=453$ TKAs) [12] and we decided to include this study as it was a large study that reported on the complications after TKA in patients with PVNS even though the study did not report on the pre-operative and post-operative functional outcomes. The range of follow-up in these studies was from 0.2 to 35 years. Using the STROBE checklist, the four articles by Houdek et al. [13], Casp et al. [12], Lei et al. [14] and Su et al. [15] scored a maximum score of $100 \%$. The article by Verspoor et al. [16] scored $97 \%$ as there was no usage of sensitivity analyses. However, this 
article was still included as it reported relevant information on recurrence and complication of TKA. The quality scores based on the percentage of the STROBE checklist fulfilment for each article are illustrated in Table 1.

\section{Statistical analysis}

The results were summarized using descriptive statistics for continuous variables, frequencies and percentages for categorical variables. Microsoft Excel, 2016 version (Microsoft Corporation, Redmond, WA, USA) was used for data analysis.

\section{Results}

Search results

The initial literature search identified 111 articles, of which 36 were duplicated articles. After screening the remaining 75 articles, a total of six studies satisfied the eligibility criteria. Two articles, Houdek et al. [13] and Hamlin et al. [17], were published by the same organization 11 years apart. We contacted the authors to clarify whether there was any data overlap, but they were unable to confirm or deny this. We, thus, elected to omit the article by Hamlin et al. [17] as it reported on the smaller series. In the end, five studies were included in our data extraction. All five studies included postoperative complications, four studies included the functional outcome in terms of Knee Society Score (KSS) and post-operative range of motion (ROM) and three studies included the pre-operative ROM. Figure 1 outlines the search strategy.

\section{Cohort characteristics}

The studies included 552 TKAs; however, only 98 patients (99 TKAs) had reported functional outcomes. Among the 552 TKAs, 83 patients (84 TKAs) had DPVNS and 15 had L-PVNS, while the remaining 453 patients from the study by Casp et al. were not characterized by the disease subtype [12]. The mean patient age of the four studies was 61 years (range 33-94). Authors Casp et al. [12] did not provide a mean patient age and only included a range of ages in their study. Overall, the mean follow-up period was 61.1 months (range 0.2-35 years). Again, as Casp et al. [12] did not provide a mean age and follow-up period, this was omitted from the results above.

\section{Outcome analysis \\ Functional outcome}

Three studies reported a pre-operative and postoperative comparison of the KSS and demonstrated a mean improvement of 26.79 and 39.11 points postoperatively, in functional and clinical KSS respectively. Casp et al. [12] and Verspoor et al. [16] did not provide the pre-operative KSS.

Table 1 Studies included, study size, Knee Society Score (KSS), range of movement (ROM), stiffness, recurrence and quality assessment

\begin{tabular}{|c|c|c|c|c|c|c|c|c|c|c|c|}
\hline Author & $\begin{array}{l}\text { Year } \\
\text { of } \\
\text { study }\end{array}$ & Study size & $\begin{array}{l}\text { KSS } \\
\text { (functional) }\end{array}$ & $\begin{array}{l}\text { KSS } \\
\text { (clinical) }\end{array}$ & $\begin{array}{l}\text { ROM } \\
\text { pre- } \\
\text { op }\end{array}$ & $\begin{array}{l}\text { ROM } \\
\text { post- } \\
\text { op }\end{array}$ & $\begin{array}{l}\text { Mean } \\
\text { ROM } \\
\text { (pre- } \\
\text { op) }\end{array}$ & $\begin{array}{l}\text { Mean ROM } \\
\text { (post-op) }\end{array}$ & Stiffness & Recurrence & $\begin{array}{l}\text { Quality } \\
\text { assessment }\end{array}$ \\
\hline $\begin{array}{l}\text { Houdek } \\
\text { et al. [13] }\end{array}$ & 2017 & $\begin{array}{l}48 \text { TKAs } \\
\text { D-PVNS: } 40 \\
\text { L-PVNS: } 8\end{array}$ & 45 to 62 & 54 to 87 & $\begin{array}{l}30- \\
35^{\circ}\end{array}$ & $\begin{array}{l}60- \\
130^{\circ}\end{array}$ & $99^{\circ}$ & $101^{\circ}$ & 13 knees & 6 knees & ++ \\
\hline $\begin{array}{l}\text { Su et al. } \\
\text { [15] }\end{array}$ & 2019 & $\begin{array}{l}28 \text { TKAs } \\
\text { D-PVNS: } 28 \\
\text { L-PVNS: } 0\end{array}$ & 48.9 to 84.6 & $\begin{array}{l}38.9 \text { to } \\
84.4\end{array}$ & $\begin{array}{l}60- \\
100^{\circ}\end{array}$ & $\begin{array}{l}90- \\
130^{\circ}\end{array}$ & $86.1^{\circ}$ & $107^{\circ}$ & 0 knees & 0 knees & ++ \\
\hline $\begin{array}{l}\text { Verspoor } \\
\text { et al. [16] }\end{array}$ & 2016 & $\begin{array}{l}12 \text { TKAs } \\
\text { D-PVNS: } 8 \\
\text { L-PVNS: } 4\end{array}$ & $\begin{array}{l}70.45 \\
\text { (post-op } \\
\text { only) }\end{array}$ & $\begin{array}{l}77.6 \\
\text { (post-op } \\
\text { only) }\end{array}$ & NR & $N R$ & $N R$ & NR & 1 knee & 1 knee & ++ \\
\hline $\begin{array}{l}\text { Lei et al. } \\
\text { [14] }\end{array}$ & 2016 & $\begin{array}{l}11 \text { TKAS } \\
\text { D-PVNS: } 8 \\
\text { L-PVNS: } 3\end{array}$ & 35.0 to 81.8 & $\begin{array}{l}40.5 \text { to } \\
90\end{array}$ & $\begin{array}{l}60- \\
100^{\circ}\end{array}$ & $\begin{array}{l}95- \\
120^{\circ}\end{array}$ & $80.5^{\circ}$ & $109.5^{\circ}$ & 0 knees & 0 knee & ++ \\
\hline \multirow{2}{*}{$\begin{array}{l}\text { Casp } \\
\text { et al. [12] }\end{array}$} & 2018 & 453 TKAs & NR & NR & NR & NR & $N R$ & $\mathrm{NR}$ & 31 knees & NR & ++ \\
\hline & & $\begin{array}{l}\text { Total: } \\
\text { 99 TKAs (552 TKAs } \\
\text { including Casp et al.) } \\
\text { D-PVNS: } 84 \\
\text { L-PVNS: } 15\end{array}$ & 74.71 & 84.75 & & & $92.51^{\circ}$ & $104.01^{\circ}$ & $\begin{array}{l}45 \\
\text { knees }\end{array}$ & 7 knees & \\
\hline
\end{tabular}

${ }^{a}$ Quality assessment of included articles (percentage of Strengthening the Reporting of Observational Studies in Epidemiology (STROBE) checklist met, $<50 \%=-$, $50-80 \%=+,>80 \%=++$ ). The STROBE checklist is available at https://www.strobe-statement.org/index.php?id=available-checklists TKA total knee replacement, D-PVNS diffuse pigmented villonodular synovitis, KSS Knee Society Score, L-PVNS localized pigmented villonodular synovitis, NR not reported, pre-op pre-operative, post-op post-operative, ROM range of motion 


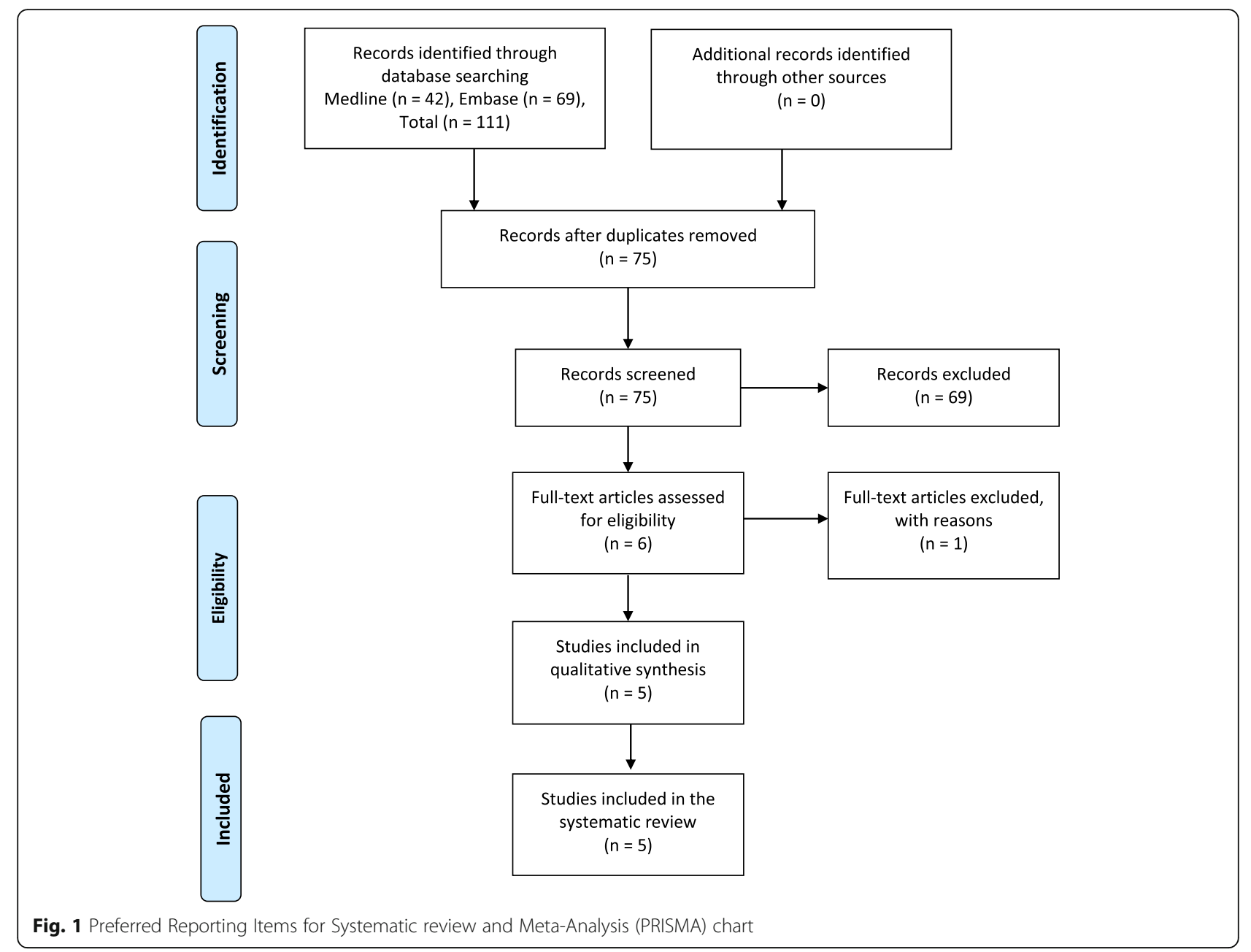

\section{Pre-operative and post-operative range of motion}

Both studies by Lei et al. [14] and Su et al. [15] showed an average of a $32^{\circ}$ improvement in post-operative ROM. Houdek et al. [13] reported no significant changes in the pre-operative and post-operative $\operatorname{ROM}(p=0.72)$. The study by Casp et al. [12] and Verspoor et al. [16] did not report on the ROM.

\section{Stiffness}

Stiffness or decreased knee range was defined by authors Houdek et al. [13] as a flexion contracture of $\geq 15^{\circ}$ or flexion $<90^{\circ}$. There were 35 cases $(6.3 \%)$ of stiffness within the 1-year post-operative period among the five studies included. The study by Casp et al. [12] utilized the current procedural terminology (CPT) coding system to identify patients who underwent TKA and had a diagnosis of PVNS or a procedure for stiffness within 1 year post-operatively. They noted a significant rate of stiffness in the PVNS group of $6.84 \%$ ( $n=31$ patients) compared to $4.69 \%$ ( $n=85$ patients) in the control group with osteoarthritis (odds ratio $(\mathrm{OR}) 1.48, p$ value $=0.023$ )

\section{Infection}

In total, there were a total of 16 infections (2.9\%) in our patient population. Authors Casp et al. [12] utilized CPT codes to identify any cases of infection, while authors Houdek et al. [13] identified infection during their follow-up period. The remaining three authors reported that there were no infections noted during the follow-up period.

\section{Recurrence}

"Symptoms of disease recurrence" was defined by authors Houdek et al. [13] as recurrent effusions, lytic formations and hemarthrosis. Authors Su et al. [15] defined it as worsening pain with or without a decrease in ROM or the finding of a new palpable mass. All patients included in the study were followed up in clinic and were monitored for disease recurrence. Houdek et al. [13] utilized plain radiography to diagnose recurrence, Verspoor et al. [16] utilized joint ultrasound and $\mathrm{Su}$ et al. [15] utilized magnetic resonance imaging (MRI). Excluding the Casp et al. [17] paper, which did not report on 
recurrence rates, the recurrence rate following TKA in our review was $7.1 \%$ (seven patients), six patients from the Houdek et al. [13] study and one patient from the Verspoor et al. study [16]; with a mean of 6 years (range 2-12 years). All seven patients who had recurrence had active D-PVNS. There were no reported cases of recurrence in L-PVNS.

\section{Revision rate}

Revision was described as the removal of implants with or without replacement of the materials. Symptomatic recurrence of PVNS, component loosening, tibialcomponent fracture, instability and periprosthetic infection were the main factors leading to revision TKA [13]. There was a total of 22 patients who underwent revision surgery in the five studies. The study by Casp et al. [12] reported that 11 patients underwent revision surgery post TKA; however, they noted that there was no significance ( $p$ value $=0.92)$ in increased risk of revision at 2 years compared to the osteoarthritis (OA) group in the 2 years post-operative period. Authors Verspoor et al. [16] reported that one patient underwent revision surgery 6 years post TKA for medial tibial-component loosening. Authors Houdek et al. [13] reported a total of 10 patients, with four patients having disease recurrence, three patients with component loosening and osteolysis, and the remaining indications were tibial-component fracture, instability and deep infection. Authors Lei et al. and $\mathrm{Su}$ et al. did not report on revision rates in their studies $[14,15]$.

\section{Discussion}

TKA has been shown to be a generally successful procedure in patients with PVNS and established degenerative changes and this is reflected in the improvement of post-operative functional and clinical KSS in the four studies included in this systematic review. The main complication of PVNS in our patient cohort appears to be stiffness and infection.

A systematic review and meta-analysis of case series and national registry reports with more than 15 years of follow-up by Evans et al. [18] estimated that the 25-year survival rate of TKA was $82 \%$. The study also included an analysis done by the UK Clinical Practice Research Datalink (CPRD) in 2017 which estimates that the survival rate of TKA is $89.7 \%$ (95\% confidence interval (CI) 87.5-91.5) at 20 years [18]. In comparison, implant survival rate of patients with PVNS was reported by Houdek et al. [13] to be $89 \%$ at 5 years, $80 \%$ at 10 years and $62 \%$ at 20 years. The other authors did not report on the implant survival rates.

An interesting observation from the studies was that 33 patients (34 TKAs) were diagnosed with PVNS postoperatively, through histopathological samples taken during the arthroplasty procedure due to suspicious synovial changes. This was seen in 23 out of 28 patients $(82.1 \%)$ in the Su et al. study [15] and 10 out 10 patients $(100 \%)$ in the Lei et al. study [14] and reinforces the message that intraoperative findings of synovial proliferation and reddish-brown, pigment-stained, synovial tissue should alert the operating surgeon to take tissue biopsies.

Stiffness was among the main complications post TKA in patient with PVNS. According to the UK National Joint Registry 16th Annual Report, the peak incidence for stiffness occurs between 1 and 3 years with 0.56 revisions performed per 1000 primary knee replacements (95\% CI 0.53-0.60) with the trend for the development of stiffness decreasing after the 3-year mark [19]. There were $35(6.3 \%)$ patients who presented with stiffness within 1 year post-operatively among the five studies in this review. Houdek et al. [13] highlighted that the group of patients who had undergone previous open synovectomy for PVNS had poor pre-operative knee ROM (mean $78^{\circ}$, range $50-115^{\circ}$ ) which co-related with their poor post-operative ROM; however, there appears to be no clear link between multiple interventions and increased stiffness post TKA in our patient population. Casp et al. [12] evaluated knee PVNS as a risk factor for complication after TKA. They compared patients who had undergone a TKA for knee degeneration with PVNS versus a control group consisting of patients with knee osteoarthritis and found that the PVNS group had a higher incidence of post-operative stiffness at 1 year $(6.84 \%$ versus $4.69 \%$, OR $1.73, p$ value $=0.011$ )

There was a total of 16 infected joints in our patient population. Casp et al. [12] also compared the risk of infection between the group with PVNS and the group with osteoarthritis and reported an infection rate of $3.31 \%(n=14)$ in the former versus $1.55 \%$ in the latter (OR 1.73, 95\% CI 1.31-2.30, $p$ value $=0.011)$. Houdek et al. [13] reported a single case of periprosthetic infection which was eventually addressed with revision TKA. This brings the infection rate up to $2.9 \%$ for this review. Both Lei et al. [14] and Su et al. [15] administered a cephalosporin-based antibiotic post-operatively and had no infections in their follow-up, indicating that there may be a role for extended antibiotics prophylaxis in preventing infections. However, given the very small number of patients in these studies, this claim warrants further investigations.

A total of seven patients were noted to have a recurrence of PVNS at a mean of 6 years (range 2-12 years) following the TKA. Both Houdek et al. [13] and Verspoor et al. [16] reported an association between previous surgery and the diffuse variant, with recurrence of PVNS post-operatively. It is worth noting that recurrence is a time-dependent phenomenon, and its 
incidence may increase with longer follow-up. It is also associated with the extent of the synovectomy performed during TKA and it is widely considered that total synovectomy during the TKA is critical in preventing recurrence of PVNS [14, 20]. Mollon et al. [10] performed a systematic review of surgical synovectomy in the treatment of PVNS and reported that open synovectomy or synovectomy combined with peri-operative radiotherapy is associated with a reduced rate of recurrence of PVNS. Post-operative radiotherapy could, hence, be considered as an adjunct to synovectomy following TKA for PVNS, with a view to further suppressing the incidence of recurrence.

Post-operative recurrence of PVNS can be identified with MRI, using metal artefact reduction sequence that optimizes the visualization of periprosthetic soft tissues. MRI can play an important role during post-operative surveillance as it is highly sensitive and non-invasive. Relevant findings are a mass or diffuse synovitis of low signal intensity, both of which warrant close follow-up [21].

\section{Limitations}

This systematic review has limitations. First, we have reported the pertinent complications, but recognize that there is a time-dependent bias, which, due to the relatively short follow-up, may lead to underrepresentation of their true incidence. Second, the available studies were characterized by having a low level of evidence as well as a lack of a complete uniformity in reporting outcomes. Additionally, the Casp et al. [12] study did not look at the functional outcome of TKA in PVNS; however, we have included it in our review as the paper was a large study looking at the complications post TKA in patients with PVNS. Lastly, due to disease rarity, there is a lack of literature available on TKA in PVNS. As a result, a meta-analysis was not performed.

\section{Conclusion}

The findings of this review support the use of TKA to alleviate the functional limitations and pain due to knee degeneration in patients with PVNS. The operating surgeon should be aware of the increased risk of postoperative stiffness, as well as a potentially higher risk of infection. Implant survival should also be considered inferior to the one expected for the general population undergoing TKA.

\footnotetext{
Abbreviations

PVNS: Pigmented villonodular synovitis; L-PVNS: Localized pigmented villonodular synovitis; D-PVNS: Diffuse pigmented villonodular synovitis; TKA: Total knee arthroplasty; PICO criteria for systematic reviews : Population, Intervention, Comparison and Outcomes; ROM: Range of motion; KSS: Knee Society Score; CPRD: Clinical Practice Research Datalink; STROBE: Strengthening the Reporting of Observational Studies in Epidemiology
}

\section{Acknowledgements}

The library staff from both Barts Health NHS Trust and Oxford University Hospitals NHS Foundation Trust contributed by helping out with the literature search for this systematic review.

\section{Authors' contributions}

$Y C T$ and $K T$ designed and performed the research and analyzed the data. YCT and JYT collected the data and contributed equally to the write-up of the manuscript. KT supervised the write-up of this manuscript. All authors read and approved the final manuscript.

\section{Funding}

No funding was obtained for this research.

\section{Availability of data and materials}

All data generated or analyzed during this study are included in this published article.

\section{Ethics approval and consent to participate}

This is a systematic review of the literature and no ethical approval was necessary for this study.

\section{Consent for publication}

Not applicable.

\section{Competing interests}

The authors declare they have no competing interests.

\section{Author details}

'Whipps Cross University Hospital, Barts Health NHS Trust, Whipps Cross Road, Leytonstone, London E11 1NR, UK. ${ }^{2}$ John Radcliffe Hospital, Oxford University Hospitals NHS Foundation Trust, Headley Way, Headington, Oxford OX3 9DU, UK. ${ }^{3}$ Orthopaedics Department, Whipps Cross University Hospital, Barts Health NHS Trust, Whipps Cross Road, Leytonstone, London E11 1NR, UK.

Received: 1 July 2020 Accepted: 7 February 2021

Published online: 25 February 2021

\section{References}

1. Gaillard F. Pigmented villonodular synovitis | Radiology Reference Article | Radiopaedia.org. Radiopaedia. Available from: https://radiopaedia.org/a rticles/pigmented-villonodular-synovitis?lang=gb. [cited 28 Sept 2020]

2. Verspoor FGM, Zee AAG, Hannink G, van der Geest ICM, Veth RPH, HWB S (2014) Long-term follow-up results of primary and recurrent pigmented villonodular synovitis. Rheumatology (Oxford) 53(11):2063-2070 Available from: https://academic.oup.com/rheumatology/article/53/11/2063/1793301. [cited 28 Sept 2020]

3. Strading H (2015) Pigmented villonodular synovitis (PVNS). Oxford University Hospitals NHS Trust. Available from: https:/www.ouh.nhs.uk/patient-guide/ leaflets/files/12241PPVNS.pdf. [cited 28 Sept 2020]

4. Sakkers RJ, de Jong D, van der Heul RO (1991) X-chromosome inactivation in patients who have pigmented villonodular synovitis. J Bone Joint Surg Am 73(10):1532-1536

5. Galli M, Ciriello V, Menghi A, Perisano C, Maccauro G, Marzetti E (2012) Localized pigmented villonodular synovitis of the anterior cruciate ligament of the knee: an exceptional presentation of a rare disease with neoplastic and inflammatory features. Int J Immunopathol Pharmacol 25(4):1131-1136

6. Rao AS, Vigorita VJ (1984) Pigmented villonodular synovitis (giant-cell tumor of the tendon sheath and synovial membrane). A review of eighty-one cases. J Bone Joint Surg Am 66(1):76-94

7. Dal Cin P, Sciot R, Samson I, De Smet L, De Wever I, Van Damme B et al (1994) Cytogenetic characterization of tenosynovial giant cell tumors (nodular tenosynovitis). Cancer Res 54(15):3986-3987

8. Fecek C, Carter KR (2020) Pigmented villonodular synovitis. In: StatPearls. StatPearls Publishing, Treasure Island Available from: http://www.ncbi.nlm. nih.gov/books/NBK549850/. [cited 14 Mar 2020]

9. Aurégan J-C, Klouche S, Bohu Y, Lefèvre N, Herman S, Hardy P (2014) Treatment of pigmented villonodular synovitis of the knee. Arthroscopy 30(10):1327-1341 Available from: http://www.sciencedirect.com/science/a rticle/pii/S0749806314004046. [cited 28 Sept 2020] 
10. Mollon B, Lee A, Busse JW, Griffin AM, Ferguson PC, Wunder JS et al (2015) The effect of surgical synovectomy and radiotherapy on the rate of recurrence of pigmented villonodular synovitis of the knee. Bone Joint J 97B(4):550-557 Available from: https://online.boneandjoint.org.uk/doi/full/1 0.1302/0301-620X.97B4.34907. [cited 15 Mar 2020]

11. Elm E, von ADG, Egger M, Pocock SJ, Gøtzsche PC, Vandenbroucke JP (2007) The Strengthening the Reporting of Observational Studies in Epidemiology (STROBE) statement: guidelines for reporting observational studies. Lancet 370(9596):1453-1457 [cited 9 Jan 2021]

12. Casp AJ, Browne JA, Durig NE, Werner BC (2019) Complications after total knee arthroplasty in patients with pigmented villonodular synovitis. J Arthroplasty 34(1):36-39 Available from: https://www.arthroplastyjournal. org/article/S0883-5403(18)30745-9/abstract. [cited 28 Mar 2020]

13. Houdek MT, Scorianz M, Wyles CC, Trousdale RT, Sim FH, Taunton MJ (2017) Long-term outcome of knee arthroplasty in the setting of pigmented villonodular synovitis. Knee. 24(4):851-855

14. Lei P, Sun R, Liu H, Zhu J, Wen T, Hu Y (2017) Prognosis of advanced tenosynovial giant cell tumor of the knee diagnosed during total knee arthroplasty. J Arthroplasty 32(6):1850-1855 Available from: https:// linkinghub.elsevier.com/retrieve/pii/S0883540317300013. [cited 25 Jun 2020]

15. Su W, Zhou Y, Lu W, Zeng M, Hu Y, Xie J (2019) Short-term outcomes of synovectomy and total knee replacement in patients with diffuse-type pigmented villonodular synovitis. J Knee Surg. https://doi.org/10.1055/s-003 9-1694736 PMID: 31434148. [cited 28 Sept 2020]

16. Verspoor FGM, Hannink G, Scholte A, Van Der Geest ICM, HWB S (2016) Arthroplasty for tenosynovial giant cell tumors. Acta Orthop 87(5):497-503 Available from: https:/www.ncbi.nlm.nih.gov/pmc/articles/PMC5016909/. [cited 13 Mar 2020]

17. Hamlin BR, Duffy GP, Trousdale RT, Morrey BF (1998) Total knee arthroplasty in patients who have pigmented villonodular synovitis. J Bone Joint Surg Am 80(1):76-82

18. Evans JT, Walker RW, Evans JP, Blom AW, Sayers A, Whitehouse MR (2019) How long does a knee replacement last? A systematic review and metaanalysis of case series and national registry reports with more than 15 years of follow-up. Lancet 393(10172):655-663 Available from: https://linkinghub. elsevier.com/retrieve/pii/S0140673618325315. [cited 25 Jun 2020]

19. The NJR Editorial Board (2019) 16th Annual Report 2019 National Joint Registry for England. National Joint Registry, Wales, Northern Ireland and the Isle of Man Available from: https://reports.njicentre.org.uk/Portals/0/ PDFdownloads/NJR\%2016th\%20Annual\%20Report\%202019.pdf. [cited 25 Jun 2020]

20. Scott WN (2011) Insall \& Scott surgery of the knee, 5th edn. Churchill Livingstone, London p 1504

21. Friedman T, Chen T, Chang A (2013) MRI diagnosis of recurrent pigmented villonodular synovitis following total joint arthroplasty. HSS J 9(1):100-105 Available from: https://www.ncbi.nlm.nih.gov/pmc/articles/PMC3640717/. [cited 25 Jun 2020]

\section{Publisher's Note}

Springer Nature remains neutral with regard to jurisdictional claims in published maps and institutional affiliations.

Ready to submit your research? Choose BMC and benefit from:

- fast, convenient online submission

- thorough peer review by experienced researchers in your field

- rapid publication on acceptance

- support for research data, including large and complex data types

- gold Open Access which fosters wider collaboration and increased citations

- maximum visibility for your research: over $100 \mathrm{M}$ website views per year

At $\mathrm{BMC}$, research is always in progress.

Learn more biomedcentral.com/submissions 